\title{
Distance Learning during Lockdown: Satisfaction Assessment among Moroccan Trainee Teachers
}

\author{
Zineb Boumaaize, Youssef El Madhi, Abdelmajid Soulaymani, Bouazza El Wahbi, and Hanan El \\ Faylali
}

\begin{abstract}
Like everywhere in the world, the sudden onset of the coronavirus pandemic and the consequent closure of schools has imposed distance education as a compulsory alternative. Therefore, teachers have switched to distance education; students have been invited to join the platforms set up. Similarly, Regional Center for Education and Training (CRMEF) has been mobilized to ensure the continuity of the pre-service training for future teachers. This research aims to assess the distance education satisfaction of future teachers during confinement. A descriptive study was conducted by using the Google Forms tool. No less than 360 trainee teachers from the Rabat-Salé-Kenitra Regional Center (CRMEF) participated in the study. A qualitative approach was carried out to develop the construct. After validation of the questionnaire by the research committee, the questionnaire was self-administered. The reliability of the questionnaire was determined. A total of 360 responses were received $(30 \%$ men and $70 \%$ women). Cronbach's alpha of the questionnaire turns out to be 0.8 . On the whole, $58.33 \%$ of the confined trainees were dissatisfied about distance learning. $60 \%$ of the participants did not have computer equipment, while $\mathbf{7 3 . 3 3 \%}$ reported that they have connection and network problems. Switching to distance learning was not a choice. Remains the best solution to complete the modules of the qualifying training of trainee teachers before their assignment. Empirical research findings and recommendations need to be taken into consideration to practice this approach in the post-pandemic period.
\end{abstract}

Index Terms-Covid-19, CRMEF, distance Learning, trainee teacher, satisfaction.

\section{INTRODUCTION}

Distance learning has a history spanning almost two centuries [1]. Since the 19th century, distance education has been in the form of correspondence courses for students who could not attend a school like traditional students. Distance learning is the major concerns of the scientific community, therefore research in this field becoming more and more intense [2].

Manuscript received February 19, 2021; revised June 1, 2021.

Zineb Boumaaize and Hanan El Faylali are with Laboratory of Informatics Systems and Optimization, Faculty of Science, Ibn Tofail University, Kénitra, Morocco (e-mail: zineb.boumaaize@uit.ac.ma, hanan.elfaylali@uit.ac.ma).

Abdelmajid Soulaymani and Bouazza El Wahbi are with Research Laboratory: Education, Environment \& Health (EES) at CRMEF Rabat / Salé / Kenitra, and with Laboratory of Genetics and Biometrics, Faculty of Science, Ibn Tofail University, Kénitra, Morocco (e-mail: youssmad@yahoo.fr, soulaymani@uit.ac.ma).

Bouazza El Wahbia is with Laboratory of Analysis, Geometry and Applications, Faculty of Science, Ibn Tofail University, Kénitra, Morocco (e-mail: belwahbi@yahoo.fr).
Before the emergence of covid-19 caused by the new SARS-CoV-2 virus [2], Morocco expressed its strong will to integrate Information and Communication Technologies (ICTs) in the education system in order to keep up with the universal technological evolution [3]. To initiate such an approach, Moroccan Ministry of National Education, Vocational training, Higher Education and Scientific Research, has launched numerous actions, namely the GENIE program (GENeralization of Information and communication technologies in Education) (2005-2016) [4], the Nafida project (2008), the national portal (Taalimtice in 2011), and the Varen project (2013).

In the era of the Coronavirus, distance learning had become an inescapable reality, the solution that is the consensus in Morocco as far as the international is concerned [5]. In order to curb a potential spread of the Covid-19 pandemic, the Ministry of National Education, Vocational training, Higher Education and Scientific Research suspended face-to-face courses effective 16 March 2020 until further notice. After shut down, all courses will delivered remotely. The ministry of education launched digital learning platforms (Taalim.ma, TelmidTice) to be available for students and academics. In the same way, the Broadcasting and Television National Company (SNRT) suspended their normal broadcasts and dedicated their Television channels ((Amazighiya, Arriyadia, Laayoune and Athaqafia TV) to support remote education in sight to ensure continuity until the end of the academic year [6]. To highlight the Ministry of Education achievements, a press release announced that number 400,000 of virtual classes has created on the digital platform until April 1st, for public schools, with a coverage rate of $52 \%$. For private schools, the number of virtual classes has reached 30,000, with a coverage rate of $15 \%$ [7].

Likewise, future teachers training has affected by the health crisis. They have lost not only access to face-to-face training but also to the practical training experience of teaching in the classroom scheduled in the second semester [8]. To adapt to this exceptional situation, the Regional Centers for Education and Training Professions (CRMEFs) [9] provided training for trainee teachers through file transfer, instant messaging and the creation of discussion boxes in secure platforms connected to Microsoft and Classroom to facilitate teamwork. Other innovative solutions (Zoom, Google Teams, Skype, etc.) have been implemented to optimize the educational efforts made [10]. Also putting at their service the e-Takwine portal, a MOOC distance learning device that aims to develop the professional skills of future teachers. This unpredictable shift towards distance education has raised many questions, including accessibility 
in its various dimensions, the availability of digital tools and the satisfaction of the AREF's trainee teachers. Since any change depends on the motivational aspect (intention to do), the professional aspect (competence to do) and the operational aspect (conditions to do), it is contrary to common sense to think that all trainee teachers will be satisfied with this new learning approach. The Socio-demographic factors, home environment and their family situations will have a direct impact on their involvement and may even affect their professional learning. In this regard, several studies on satisfaction with distance education have been identified in the literature [11].

According to $\mathrm{Ku}$ et al. [12], satisfaction plays a crucial role in the success of distance learning. It is predicted by several key factors including motivation, self-efficacy, interaction with the teacher, course structure, and learning style [13]. Therefore, the perception of future teachers of the content presented online is one of the key factors in assessing their satisfaction.

Based on this observation and awareness of the importance of distance education in these confinement conditions of containment dictated by this pandemic. This study attempts to answer the following questions:

- What e-learning challenges experienced by trainee teachers during lockdown?

- Did the trainee teachers have the necessary ICT skills?

- Were future teachers satisfied and implicated after implementation of this approach?

The main objective of this study is to investigate the perceptions of trainee teachers about the distance education allocated to them during the covid-19 pandemic. Also, the evaluation of the future teacher's satisfaction toward new training method with a view to proposing recommendations likely to improve the quality of the distance learning system.

\section{Materials AND MethoD}

\section{A. Participants}

360 trainee teachers belonging to the CRMEF of the Rabat-Salé-Kénitra region answered to questionnaire $(30 \%$ men, $70 \%$ women). The average age is $28.30 \pm 5.99$.

$69 \%$ of trainee's are single, $31 \%$ married. $63.3 \%$ of the them have a bachelor's degree, $31.7 \%$ have a master's degree and $5 \%$ have a $\mathrm{PhD}$ degree. $75 \%$ in the primary cycle, $25 \%$ in the secondary cycle.

\section{B. Instruments}

Based on an exploratory qualitative study, the questionnaire items were elaborated and administered via Google forms (Due to COVID-19 pandemic). This survey contains three sections. The first includes socio-demographic and professional variables including gender, age, family situation, university level and training cycle at the regional center.

The second section generates information on living conditions during lockdown (housing area, number of people living under the same house, workspace, etc.). As for the last section, all the questions were structured around the remote training load, the numerical tools used in training, the degree of concentration, the implication and satisfaction of the trainee's community.

\section{Data Analysis}

From April to May, the collected data was coded directly on SPSS statistics version 25.

Out of 394 responses, 34 were not coded for several reasons: (Repetition / empty response / irrelevant responses.). 360 trainee teachers (30\% men, $70 \%$ women) met the eligibility criteria of our study. The reliability of the questionnaire was calculated by recording a Cronbach's alpha of 0.8. The results generated from the descriptive analysis will be presented below.

\section{RESUlTS}

As can been seen in the Table I, the results revealed that lockdown are not experienced in the same way. Due to the pandemic situation, $75 \%$ of the trainee teachers were confined with 4 to 7 people in the same house. The situation is more delicate in an overcrowded house with few rooms and in the presence of children who are less autonomous.

TABLE I: LIVING CONDITIONS INFORMATION

\begin{tabular}{|c|c|c|}
\hline & Frequency & Percentage \\
\hline \multicolumn{3}{|c|}{ House Area } \\
\hline Less than $80 \mathrm{~m}^{2}$ & 132 & $36.67 \%$ \\
\hline Between $80 \mathrm{~m}^{2}$ and $100 \mathrm{~m}^{2}$ & 144 & $40 \%$ \\
\hline More than $100 \mathrm{~m}^{2}$ & 84 & $23.33 \%$ \\
\hline \multicolumn{3}{|c|}{ Home airy zone } \\
\hline Yes & 204 & $56.67 \%$ \\
\hline No & 156 & $43.33 \%$ \\
\hline \multicolumn{3}{|c|}{ People locked down in same house } \\
\hline [1-4] & 60 & $16.67 \%$ \\
\hline [4-8] & 270 & $75 \%$ \\
\hline$>8$ pers & 30 & $8.33 \%$ \\
\hline \multicolumn{3}{|c|}{ Possess a house workspace } \\
\hline Yes & 198 & $55 \%$ \\
\hline No & 162 & $45 \%$ \\
\hline
\end{tabular}

$36.6 \%$ lived in the houses less than $80 \mathrm{~m} 2$, while $40 \%$ of them were confined in surface oscillating between 80 and $100 \mathrm{~m} 2.56 .67 \%$ have home airy zone (garden, terrace, balcony, etc.) to entertain or change air.

In this period, trainees were forced to relocate the training center to their homes, in which case the trainee teacher is supposed to set up his or her own home workspace. According to that, $55 \%$ of the respondents do not have their own workspace to study, concentrate and even interact with the trainer.

To explore this field, we asked participants about e-training constraints. They revealed that the major barriers to follow distance training were resumed on lack of digital skills $(80 \%)$, lack of material $(60 \%)$, Connection and network problems $(73.33 \%)$, unfamiliarity with online learning (78.33\%) and unsuitable training timetable (68.33\%) (Table II).

In order to understand the dissatisfaction sense and trainees implication, Table III shows that more than half $(58.3 \%)$ of the respondents were dissatisfied with this new learning method, compared to $41.7 \%$ who expressed their 
satisfaction. Therefore, the majority of trainees (43.33\%) were not to less involved in the online courses.

\begin{tabular}{|c|c|c|}
\hline & Frequency & Percentage \\
\hline \multicolumn{3}{|c|}{ Digital skills } \\
\hline Yes & 72 & $20 \%$ \\
\hline No & 288 & $80 \%$ \\
\hline \multicolumn{3}{|c|}{ Material availability } \\
\hline Yes & 144 & $40 \%$ \\
\hline No & 216 & $60 \%$ \\
\hline \multicolumn{3}{|c|}{ Connection and network problems } \\
\hline Yes & 264 & $73.33 \%$ \\
\hline No & 96 & $26.67 \%$ \\
\hline \multicolumn{3}{|c|}{ accustomed to digital courses } \\
\hline Yes & 78 & $21.67 \%$ \\
\hline No & 282 & $78.33 \%$ \\
\hline \multicolumn{3}{|c|}{ Training timetable } \\
\hline Not suitable at all & 60 & $16.67 \%$ \\
\hline a little suitable & 246 & $68.33 \%$ \\
\hline Always suitable & 54 & $15 \%$ \\
\hline
\end{tabular}

TABLE III: TRAINEE TEACHERS SATISFACTION AND IMPLICATION LEVEL Frequency Percentage

\begin{tabular}{ccc}
\hline \multicolumn{3}{c}{ E-learning satisfaction } \\
\hline Yes & 150 & $41.7 \%$ \\
\hline No & 210 & $58.3 \%$ \\
\hline \multicolumn{3}{c}{ Implication Degree }
\end{tabular}

\begin{tabular}{clc}
\hline Not implicated at all & 36 & $10 \%$ \\
\hline Less implicated & 120 & $33.33 \%$ \\
\hline Moderately implicated & 132 & $36.67 \%$ \\
\hline implicated & 48 & $13.33 \%$ \\
\hline Very implicated & 24 & $6.67 \%$ \\
\hline
\end{tabular}

To understand the real reasons of dissatisfaction sense, $48.28 \%$ of trainees reveals that it is related to teaching pace and methods. In equal part, $20.69 \%$ of them confirm that it is related to connection problem, lack of equipment, family responsibilities and home environment. On the other way, $10.34 \%$ said that the asynchronous courses discourage trainees and limit interaction between trainer and trainees.

Depending to results presented above, it was necessary to investigate the relationship between trainee teachers satisfaction and other survey's components. The results showed that all relationships are significant. Trainee teachers satisfaction are related to their custom to follow the training online $(r=-0.280, p<0.05)$ and lack of equipment (Laptop, tablet, ...) $(r=-0.345, p<0.01)$. In lock down period, poor living conditions affect directly the trainee's satisfaction sense $(r=-0.337, p<0.01)$.

About the relationship between satisfaction and involvement $(r=0.422, p<0.001)$, concentration degree $(r=$ $0.375, p<0.001)$, it should be mentioned that training satisfaction sense affected implicitly trainee behavior.

\section{DISCUSSION}

Like all countries affected by SARS-CoV-2 pandemic, Morocco decided to switch onsite learning to online learning for the purposes of ensuring the pedagogical continuity. For that reason, we have launched a quantitative study by distributing a questionnaire in order to identify the e-training constraints and examine the trainee teacher's satisfaction. This research represent an added value to this field devoted to identifying the main factors that can influence satisfaction sense.

Based on the analyzed data, we have found that difficulties encountered by e-learning users were not only technological in nature; social factors also had an impact on how they perceived e-learning. At the pandemic period, trainees lived in very diverse environments and had to manage their social life differently than before. The majority of the Moroccan trainees were locked down in overcrowded houses ranging from $80 \mathrm{~m} 2$ to $100 \mathrm{~m} 2$. As mentioned before, Moroccan trainees were forced to move the training center to their homes and arranged a quiet zone. While, $45 \%$ of respondents were not possess a workplace to accomplish their online training program in full concentration. Namibian students enrolled for high education experienced the same situation. They lived in crowded high-density locations and claimed that the home environment may not be conductive to learning [14].

As far as the trainee's distance learning satisfaction is concerned, we were interested to highlight the constraints. Related to the literature review, several challenges related to adopting the e-learning approach were identified. These challenges were classified into four groups: 1) technological challenges, 2) individual challenges, 3) cultural challenges and 4) course challenges. We noted that these challenges depending to culture, context and readiness.

Depending to our research, the e- training barriers are presented on 5 points:

- Digital skills

- Material availability

- Connection and network problems

- accustomed to digital courses

- Training timetable

In the same vein, Tarus et al. (2015) [15] identified several challenges faced by 148 respondents drawn from three Kenyan public universities which hindering the e-learning implementation. The study's result concluded that e-learning infrastructure, lack of technical skills, inadequate internet bandwidth, lack of e-content, and lack of interest are the major barriers to e-learning implementation. However, a research conducted into 141 students in tertiary institutions from Ghana approved that social issues, lecturer issues, accessibility, learner intentions and lack of academic skills are the most important challenges faced in e-learning situation [16].

In comparison with South America, Asia and Africa, the biggest barriers are Internet network problems, lack of ICT knowledge and inexperience in using ICT equipment [17]. Mbodila, Jones and Muhandji (2013) [18] argue that the integration of ICT in teaching necessitates infrastructure issues such as access, equity, management, performance, pedagogy, quality, science, and innovation [18], [19]. Consequently, student teachers who lives in small villages not covered by Internet networks have been deprived of their right to learn [20]. 
The situation is extremely worsening in under developed countries [21]. There is no doubt that students do not have equal opportunities to study online efficiently due to different living conditions, domestic duties, and other factors. Previous research announced that only $29.2 \%$ students from Africa (e.g., Mozambique (14.4\%) and Kenya (17.8\%)) were reported a good Internet connection. Indeed, African students from Egypt and South Africa reported the limited access to the Internet and appeared least satisfied about their online learning [22].

According to this axis, three thousand thirty-seven students and two hundred thirty-one teachers from 15 Moroccan universities in different domains participated to an online learning assessment. The results reveal that students are not satisfied with the distance learning provided by the professors. The main reasons range from equipment, lack of digital skills, technical challenges to low Internet connection speed. The online course satisfaction can be also affected by perceived value, perceived quality, perceived usability and computer self-efficacy [23], [24]. According to Lucero [25] and Rovai [26], the distance learning satisfaction are related to a good courses design. It is not only arousing the interest of learners, but also promotes their interaction, encourages them to engage in the act of learning. Vonderwell and Turner (2005) [27] already noted that student satisfaction is closely related to course content and delivery, peer and teacher-student interaction, teacher support, timely feedback, clear instructions, and the nature of student assignments.

It is also mentioned that the online learning takes time and requires physical and mental performance [28]. Hence, the majority of learners are already attached to the classic approach (face-to-face training) [22]. Our study results reflected this reality; more than three quarter trainees $(78.33 \%)$ are not accustomed to this new training method because they consider that the training only takes place in the center lecture halls. Suddenly, an unexpected change came to change the blackboard to virtual sessions. Certainly, online training are more flexible but Trainers and trainees needed to manage their responsibilities and daily routine in order to cope training pressure and family concerns. This dual function may influence on the one hand their comfortability sense and the other hand their engagement into their training. Thus, an initiation to blended approach was requested before the pandemic to be transitioned smoothly.

In spite of this, nobody can ignore the efforts made by trainers to make successfully this transition and adopt this new approach in the post-pandemic period. This unexpected experience of the Regional Centers for Education and Training should be invested with several strategies undertaken to address the Constraints of online training include:

- Establishing an appropriate e-training policy to guide trainee teachers towards successful online training.

- Launching national initiatives of procuring computer equipment and accessories with promotional cost;

- Adopting the blended approach and convert their course materials to usefulness e-content.

- Developing technico-pedagogical skills and creating a powerful digital infrastructure to facilitate access to e-content.
- Creating a technical assistance team to assist professors with the task of uploading content online.

- Restructuring and improvement of the Regional Center's platform for conducting videoconferences and collecting digital resources deposited by trainers.

- Partnership of regional centers for Education and Training with Moroccan Mobile operators to offer high-speed connection box to future teachers at promotional prices.

\section{LIMITATIONS}

Notwithstanding the fact that this study discussed a current topic, some potential limitations that could be appeared and debated in future studies. First, the trainee teacher's response rate was very low in comparison to the total number of Moroccan future teachers who have accessed the regional center in 2020. Therefore, the findings' generalizability should be viewed with caution due to social and financial differences between each trainee. Secondly, this research focused essentially on trainee's satisfaction whereas the trainer's perception towards the sudden adoption of the online approach is equally important. Future research can investigate this field. Finally, individual satisfaction sense may change over time. Thus, longitudinal research is required to understand deeply the critical variables to the online learning acceptance depending to different COVID-19 pandemic crisis period.

\section{CONCLUSION}

The Covid-19 pandemic forced the world to adopt online learning. It is not an option but an obligation to ensure educational continuity. For its part, the training regional centers of future teachers pushed trainers to substitute the face-to-face learning by virtual learning. This approach made learning more flexible and not limited by distance, space, and time. Despite these advantages, trainees approved to be more satisfied by face-to-face training than online. Empirical research conducted with future teachers provides the real reasons of their choice and highlight the constraints, which hinder student to embrace e-learning. However, the Regional Centers for Education and Training, as well as all relevant stakeholders in educators training, must implement innovative pedagogical approaches that encourage trainees to use online learning not only during the training period, but also throughout their professional career.

\section{CONFLICT OF INTEREST}

The authors declare no conflict of interest.

\section{AUTHOR CONTRIBUTIONS}

All authors have contributed equally to this manuscript and agreed to the final version.

\section{REFERENCES}

[1] J. M. Spector, M. D. Merrill, J. V. Merrienboer, and M. P Driscoll, "Handbook of research on educational communications and technology," New York, London: Lawrence Erlbaum Associates, 3rd ed., 2008. 
[2] WHO. Coronavirus disease (COVID-2019) situation reports. World Health Organization, Geneva. [Online]. Available: https://www.who.int/emergencies/diseases/novel-coronavirus-2019/sit uation-reports/

[3] A. Nejjari and I. Bakkali, "The use of ICT in Moroccan schools: State and perspectives," Hermès, La Revue, pp. 55-61, 2017.

[4] D. Louiz, "Distance learning in Morocco at the time of Covid-19," EpiNet Association n²05, May 2020.

[5] M. Benseddik, "The Moroccan university under the test of Covid-19," Le Libellio d' AEGIS, vol. 16, pp. 37-44, 2020.

[6] A. Ibourk and T. Ghazi, "An online school of the future, equity and quality for all: Reflections on a well-designed model," Policy Center for the New South, Policy Paper, pp. 20-12, May 2020.

[7] Medias24, "Coronavirus. Internet and television for distance learning in Morocco," Medias24, March 15, 2020.

[8] UNESCO, "Supporting teachers and education personnel during times of crisis," Issue note $\mathrm{n}^{\circ} 2.2$, April 2020

[9] A. Ouasri, "The training of science teachers in Morocco: history, state and perspectives," Educational Journal of the University of Patras UNESCO Chair, pp. 44-53, 2019.

[10] Z. Almarzooq, M. Lopes, and A. Kochar, "Virtual learning during the COVID-19 pandemic: A disruptive technology in graduate medical education," Journal of the American College of Cardiology, 2020.

[11] K. Al-Mohair Hani and S. Alwahaishi, "Study on students experiences about online teaching during COVID-19 Outbreak," Technium Social Sciences Journal, vol. 8, pp. 102-116, June 2020.

[12] Y.-C. Kuo, A. E. Walker, K. E. E. Schroder, and B. R. Belland, "Interaction, Internet self-efficacy, and self-regulated learning as predictors of student satisfaction in online education courses," The Internet and Higher Education, vol. 20, pp. 35-50, 2014.

[13] S. B. Eom, N. Ashill, and H. J. Wen, "The determinants of students perceived learning outcomes and satisfaction in university online education: An empirical investigation," Decision Sciences Journal of Innovative Education, vol. 4, no. 2, pp. 215-235, 2006.

[14] G. Kaisara and K. J. Bwalya, "Investigating the e-learning challenges faced by students during Covid-19 in Namibia," International Journal of Higher Education vol. 10, no. 1, 2021.

[15] J. K. Tarus, D. Gichoya, and A. Muumbo, "Challenges of implementing e-learning in Kenya: A case of Kenyan public universities," International Review of Research in Open and Distributed Learning, vol. 16, no. 1, 2015.

[16] E. Aboagye, J. A. Yawson, and K. N. Appiah, "COVID-19 and e-learning: The challenges of students in tertiary institutions," Social Education Research, vol. 2, no. 1, 2021.

[17] A. Aristovnik, D. Keržic, D. Ravšelj, N. Tomaževic, and L. Umek, "Impacts of the COVID-19 pandemic on life of higher education students: A global perspective," Sustainability, vol. 12, 2020, doi: $10.3390 /$ su 12208438 .

[18] M. Mbodila, T. Jones, and K. Muhandji, "Integration of ICT in education: Key challenges," International Journal of Emerging Technology and Advanced Engineering, vol. 3, no. 11, pp. 515-520, 2013.

[19] A. Ahmed, "Integrating ICT in teaching and learning at Sultan Qaboos University: Current status and future recommendations," International Journal of Information and Education Technology, vol. 10, no. 12, 2020.

[20] J. Boumaajoune. (2020). Enjeux et défis d'une numérisation précoce. [Online]. Available: http://albayane.press.ma/\%EF\%BB\%BFenjeux-et-defis-dune-numeris ation-precoce.html

[21] F. Z. Hibbi, O. Abdoun, and H. E. Khatir, "Coronavirus pandemic in Morocco: Measuring the impact of containment and improving the learning process in higher education," International Journal of Information and Education Technology, vol. 11, no. 1, 2021.

[22] V. Roach and L. Lemasters, "Satisfaction with online learning: A comparative descriptive study," Journal of Interactive Online Learning, vol. 5, pp. 317-332, 2006.
[23] C. Chiu, M. Hsu, S. Sun, T. Lin, and P. Sun, "Usability, quality, value and e-learning continuance decisions," Computers \& Education, vol. 45 , pp. 399-416, 2005

[24] D. Compeau and C. Higgins, "Computer self-efficacy: Development of a measure nd initial test," MIS Quarterly, vol. 19, no. 2, pp. 189-211, 1995.

[25] R. Lucero, "Building a positive classroom culture and climate," 2006.

[26] A. P. Rovai, "Building sense of community at a distance," International Review of Research in Open and Distributed Learning, vol. 3, no. 1, pp. 1-9, 2002.

[27] S. Vonderwell and S. Turner, "Active learning and preservice teachers' experience in an online course: A case study," Journal of Technology and Teacher Education, vol. 13, pp. 65-85, 2005.

[28] S. Firdoussi, M. Lachgar, H. Kabaili, A. Rochdi, D. Goujdami, and L. Firdoussi, "Assessing distance learning in higher education during the COVID-19 pandemic," Education Research International, vol. 2020.

Copyright $(2021$ by the authors. This is an open access article distributed under the Creative Commons Attribution License which permits unrestricted use, distribution, and reproduction in any medium, provided the original work is properly cited (CC BY 4.0).

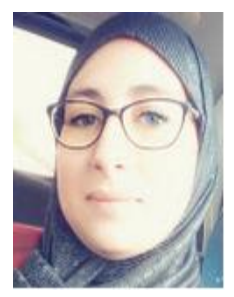

Zineb Boumaaize is a $\mathrm{Ph} . \mathrm{D}$. candidate at the Department of Laboratory of Informatics Systems and Optimization, at Ibn Tofail University. She had her master's degree on teaching professions. Her research interest includes learning and psychological teaching diseases.

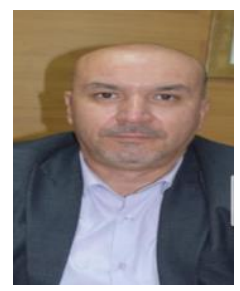

Youssef EI Madhi is a CRMEF trainer and professor at Ibn Tofail University. His current research includes the psychological studies like burnout studies, job satisfaction and occupational stress.

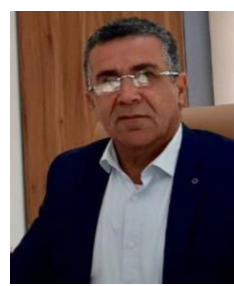

Abdelmajid Soulaymani is a professor of genetics and biometrics, Director of Phd center at Ibn Tofail University. He is a Founder and vice president of Moroccan Society of clinical and analytical toxicology. His current research includes epidemiological and toxicological research.

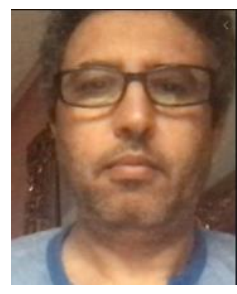

Bouazza El Wahbi is a professor of Mathematics at Ibn Tofail University. His current research includes Analysis, Geometrics research and its applications.

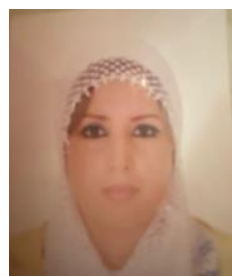

Hanan El Faylali is a professor of informatics, systems and optimization at Ibn Tofail University. Her current research includes fifth generation wireless applications. 